International Students' Cross-Cultural Adjustment: Social Selection or Social Influence?

Giovanni R. P. Sadewo ${ }^{1}$, Emiko S. Kashima ${ }^{1}$, Colin Gallagher $^{2}$, Yoshihisa Kashima ${ }^{3}$, Johan Koskinen $^{3}$

${ }^{1}$ La Trobe University

${ }^{2}$ Swinburne University of Technology

${ }^{3}$ University of Melbourne

Author Note

This research was supported by ARC Discovery Grant (DP130100845) awarded to Emiko Kashima and YoshihisaKashima. This study was part of the first author's PhD thesis, supervised by the second author. Please direct all correspondence to Dr. Giovanni Radhitio Putra Sadewo, School of Psychology \& Public Health, La Trobe University, Vic., 3086 Australia (grpsadewo@hotmail.com). We thank international students involved in this study for their participation in the study, and Theresa Greiner, Sutarimah Ampuni, Linah Helou, and Ben Chun Lam for assistance with data collection. 


\begin{abstract}
International education provides students with an opportunity to develop new social networks while they fit in to the new culture. In a three-wave longitudinal study, we investigated how social networks and psychological adjustment co-evolve within a group of international students enrolled in a coursework degree at the tertiary level. Using the Stochastic ActorOriented Model (SAOM), we identified occurrences of social selection based on the levels of psychological and sociocultural adjustment. More specifically, students tended to deselect classmates who were dissimilar in their level of psychological adjustment, and to befriend those who differed in their levels of sociocultural adjustment. In contrast, little evidence was found to suggest that features of social networks influenced students' adjustment. Potential applications of this new method to future acculturation research are suggested.
\end{abstract}

Keywords: Psychological adjustment, sociocultural adjustment, SAOM, international students, social network 


\section{International Students' Cross-Cultural Adjustment: Social Selection or Social Influence?}

Adjusting to a new culture almost always requires a transcultural traveller to develop new social networks - a set of people and the relations among them (Robins, 2015). In the case of international students, the new social networks provide them with social resources to cope with the demands of the new social and academic environment, easing their adjustment and reducing loneliness and the risk of potential depression (Cotterall, 2011; Sawir, Marginson, Deumert, Nyland, \& Ramia, 2008).

Issues associated with international students, especially their psychological and academic adaptation, have recently been highlighted in the public media in Australia, the fourth largest exporter of education in the world, where nearly 400,000 overseas students comprise a fifth of the tertiary student population (Ferguson \& Sherrell, 2019). International education is the third-largest export in the Australian economy and brings significant revenue to universities. Recognising its importance, the government and universities seek to provide protection and support services to international students to enhance their safety and offer successful study experiences. While generally high levels of satisfaction and lower attrition rates, compared to domestic students, have been reported in Australia (Ferguson \& Sherrell, 2019), it is widely recognised that international students tend to face a variety of challenges during their sojourn in the new country (Gallagher, 2013; Sherry, Thomas, \& Chui, 2010). A particularly salient issue is the difficulties in establishing personal relationships outside of their cultural group of origin (Australian Government Department of Education and Training [AGDET], 2015; Dalglish \& Chan, 2005), despite opportunities to meet new people on campuses and especially in their courses. While potential impacts of these challenges on their psychological adjustment are well-documented (Rosenthal, Russell, \& Thomson, 2006; Sawir 
et al., 2008), few studies have systematically investigated the longitudinal interplay between cross-cultural adaptation and the friendship networks that international students develop.

It is easy to imagine that those who are surrounded by many friends would feel less lonely and cope better with their academic demands than those with no friends to interact with (Sawir et al., 2008), and indeed, a few existing studies have shown that the social networks that students develop are likely to influence their cross-cultural adaptation (Hendrickson, Rosen, \& Aune, 2011; Ozer, 2015). At the same time, however, the students' psychological adjustment may also influence the development of their friendship networks. For instance, it seems feasible that students who successfully fit-in to the new university environment are approached more by their new peers for social activities or study groups. Thus, the relationship between the development of social networks and cross-cultural adaptation may involve bidirectional causal links, although relevant data are scarce.

One of the reasons for the paucity of data revealing bidirectional causal links is that conventional statistical techniques, for example generalized linear models, are unsuited for analysing social relationships that change over time, such as how social influence is transmitted across personal ties within a population while those ties themselves changing. To pursue such questions requires a statistical model developed specifically for social network analysis (Snijders, van de Bunt, \& Steglich, 2010), for example, Stochastic Actor Oriented Model (SAOM; Snijders et al., 2010). SAOM can test the bidirectional causal relationships between the changes in actor attributes (such as adjustment) and temporary changes in social ties within a given social group (e.g., an academic unit, a neighbourhood, an organisational unit). As this method views the relationships among all network members within a bounded population, the group as a whole is the unit of analysis (thus called 'whole network analysis' or 'full network analysis') and could be likened to modelling-based case analyses. 
By using SAOM and whole network analysis of an entire academic unit involving a proportion of international students, researchers can examine the causal relationships between the changes in cross-cultural adaptation and the changes in friendship ties within the unit. Such an approach is still rare in acculturation research. By taking SAOM and the wholenetwork analysis approach, the present research investigated the longitudinal co-evolution of friendship networks and cross-cultural adaptation among a group of students enrolled in the same postgraduate course at an Australian tertiary institution.

\section{A Social Network Approach to Acculturation}

In typical studies of social networks, patterns of network ties among people are analysed in relation to their personal attributes, including roles, behaviours, and psychological states. Longitudinal studies of social networks may examine dynamic changes in the pattern of network ties, addressing questions such as how personal attributes influence the shifts in network ties, and how network ties influence the changes in personal attributes. The former question concerns social selection process whereas the latter concerns social influence process. The two constitute contrasted yet parallel paths through which the temporal changes in social networks and personal attributes unfold in interaction. As such, testing both models simultaneously provides with a powerful technique in an analysis of dynamic processes (Robins, Elliott, \& Pattison, 2001).

To elaborate, through social selection, actors structure networks based on their own and others' attributes (e.g., behaviour), the attributes of the surrounding network structure (e.g., year level), and these combinations (Robins et al., 2001). Social selection involves various sub-processes, including selection (i.e., forming new ties), tie maintenance (maintaining old ties) and deselection (dissolving ties). These sub-processes may occur independently or in concert with additional network processes, such as reciprocity (actor selects another actor as a friend who will select back the same actor as a friend) and 
transitivity (i.e., friend of a friend tend to become friend; Ripley, Snijders, Boda, Vörös, \& Preciado, 2018). In contrast, through social influence processes (or social diffusion), actors change others' attributes, both intentionally and unintentionally (Marsden \& Friedkin, 1994). Social influence also involves sub-processes, including contagion (adopting a new behaviour from a network partner, and the behaviour spreading across the network), convergence of attributes toward one another, diverging and differentiating.

A major interest in social network studies can be which of the social selection and social influence, as well as their sub-processes, is at work within the population, and what attributes structure those operations. Previous research has shown social selection is more likely when network ties are structured by relatively stable attributes such as personality traits. For instance, more extraverted people tend to select more friends, whereas more agreeable people tend to be selected more by others (Selfhout et al., 2010). One longitudinal study has found that undergraduates' friendship networks developed through social selection based on their academic achievement (Dokuka, Valeeva, \& Yudkevich, 2015): students with higher (vs. lower) academic achievement selected more friends and were selected more by others. Conversely, relatively malleable attributes may play a part in both social selection and social influence processes, making the causal relationships more complex. For instance, psychological wellbeing may play a role in both social selection and social influence. As shown in previous research, depressed (vs. non-depressed) people tend to select more people who are depressed as friends (Cheadle \& Goosby, 2012; Schaefer, Kornienko, \& Fox, 2011) showing social selection, whereas connections with others who are depressed (or happy) tend to increase own level of depression (or happiness; Cheadle \& Goosby, 2012; Fowler \& Christakis, 2008; Rosenquist, Fowler, \& Christakis, 2011). To examine which of the social selection and social influence processes and sub-processes play key roles in a group of 
international students adapting to the new environment is a unique question to be tested in the field.

Indeed, SAOM models can estimate a variety of social processes that are common in social groups (Wimmer \& Lewis, 2010). Analysts can select some of them in a theory-driven manner by tying their theory and the tool together, but some controls are necessary for accounting for dependence among variables. The controls will inform a range of processes at work within the whole network. All components of SAOM also distinguishes between network patterns that arise from the internal processes of the system to organise itself (i.e., endogenous effect) such as reciprocity and transitivity (see above), and network patterns that arise from attributes that are external to the system itself (i.e., exogenous effects) such as homophily and heterophily (Lusher, Koskinen, \& Robins, 2013; See under method for the specific endogenous and exogenous effects that were selected in the present study). This would help analysts to compare the internal processes of distinct whole networks across projects. $^{1}$

In the present study, we selected our model components guided by both previous research on international students and the conceptual framework of SAOM in which the changes in students' friendship ties were likely driven by the attributes of actors (e.g., psychological adjustment), other students, and their relationships (e.g., similarity in adjustment levels). By taking this approach, the primary aim of the research was to disentangle the bidirectional causal relationships between the changes in students' adjustment and changes in their friendship ties within a whole network. Additional aims included broadening our understanding of how an academic unit involving a large proportion of international students evolves over time in their characteristics.

The previous literature on international students has identified two dimensions of cross-cultural adaptation, namely sociocultural adjustment and psychological adjustment. 
Sociocultural adjustment is defined as an individual's ability to 'fit in' or to negotiate social interactions successfully in the new culture (Ward, Okura, Kennedy, \& Kojima, 1998), whereas psychological adjustment refers to successful coping with the stressors encountered during a cross-cultural transition (Carp \& Carp, 1983; Ward et al., 1998). The relationship between the two dimensions of adjustment is expected to be positive although its strength varies from one study to another and across phases of adaptation (Hirai, Frazier, \& Syed, 2015; Ward et al., 1998).

\section{Hypotheses}

We developed four novel hypotheses to address how the two dimensions of adjustment co-evolve with the friendship ties over time within the given whole network. The four hypotheses were independent but complementary. The first two hypotheses concerned social selection, a network pattern arising from student attributes (i.e., levels of adjustment).

H1: Within the whole network, students tend to select a friend who is more similar to themselves in the level of psychological adjustment (i.e., homophily based on psychological adjustment in friend selection).

Homophily emphasises a shared attribute in partner selection (McPherson, SmithLovin, \& Cook, 2001). Previous research has shown that international students tend to reveal homophily based on nationality when making friends (Bochner, McLeod, \& Lin, 1977; Furnham \& Alibhai, 1985) although its implication for students' adaptation has been mixed (e.g., Ward \& Kennedy, 1993). Homophily other than the one based on nationality or region has been neglected. We predicted the homophily based on level of psychological adjustment, given the prior evidence that psychological wellbeing can influence friendship networks (e.g., Cheadle \& Goosby, 2012; Elmer, Boda, \& Stadtfeld, 2017). Students who show similar levels 
of coping may share their experiences more openly and strengthen their friendship ties (e.g., Kulik \& Mahler, 2000; Rook, Pietromonaco, \& Lewis, 1994).

As for sociocultural adjustment, however, the dynamism may differ, because students find others with skill levels that differ from their own to be more attractive (Gallagher \& Robins, 2015; Rivera, Soderstrom, \& Uzzi, 2010), at least among those with lower skills who can learn and gain benefit from friends (e.g., Moody, 2004). Thus:

H2: Within the whole network, students tend to select a friend who is less similar to themselves in the level of sociocultural adjustment (i.e., heterophily based on sociocultural adjustment in friend selection).

The next two hypotheses concerned social influence, and more specifically, the effect of a network pattern, predicated on an attribute, on adjustment:

H3: Students who become friends with a psychologically better-adjusted student will increase their level of adjustment while students who become friends with someone less-adjusted than themselves remaining relatively unaffected (i.e., contagion effect of psychological adjustment).

This hypothesis seemed justifiable because friends are generally more influential than nonfriends (e.g., Jaccard, Blanton, \& Dodge, 2005), and better-adjusted (vs. less-adjusted) students are more resilient against negative influences (Parker \& Asher, 1993; Schaefer et al., 2011). The same argument can be applied to sociocultural adjustment, thus:

H4: Students who become friends with a socio-culturally better-adjusted student will increase their level of sociocultural skills while students who become friends with someone with lower skills than themselves remaining relatively unaffected (i.e., contagion effect of sociocultural adjustment).

In addition to hypotheses, we also explored several effects of homophily based on the region of origin, international student status, student cohort, and gender. Furthermore, many 
other social processes, both endogenous and exogenous effects, were explored as controls, to understand better how the full network of students evolves.

\section{Method}

\section{Participants and Procedure}

Following approval from the research ethics committee, we identified several potential postgraduate programmes as a research target. The inclusion criteria were enrolment size (50-100 students), international enrolment (> 50\%), and the mode of teaching delivery (on-shore, face-to-face) and duration of the programme ( $>1$ year). We selected a Master of Bio-business degree that satisfied these criteria, and permission from the course coordinator was obtained. The length of this degree programme was two years (four semesters). The students completed their coursework in the first two semesters, during which they attended all classes together; they conducted independent research in the final two semesters, during which they worked individually in separate laboratories. Data collection took place three times, separated by 3-4 months: in March-April 2014 (T1), August-September 2014 (T2) and November-December 2014 (T3). As the programme allowed mid-year entry, some participants at T1 were already in their second semester of study (referred to as cohort A), while others were in their first semester (cohort B). At T2 and T3, the students in cohort A had moved on to their first research semester, whereas the students in cohort B were in the second coursework semester. Thus, the two cohorts studied in the same place in T1 but were separated in different places in $\mathrm{T} 2$ and $\mathrm{T} 3$.

The students were recruited from the first class of the semester. Those who agreed to participate were invited to complete a paper questionnaire three times in the social psychology laboratory at the same university. Of the 62 students (including 36 males) enrolled in the course (30 in cohort A, 32 in cohort B) in T1, 8 withdrew from the course soon after the semester started, reducing their number to 54. Since the impact of the eight 
students was considered minimal, they were omitted from the analysis. Of these students, 40 (74\%; including 22 males) participated at T1 (19 in cohort A, 21 in cohort B). At T2, 3 from cohort A withdrew from the study and 1 new participant (cohort B) joined the study. Thus, 38 (70\%; including 21 males) participated in the data collection at T2 and T3.

All except five participants were international students (i.e., tertiary students studying in Australia on a student visa) from 12 different countries. The largest group was Indians (37\%). Two of the local participants were Australia-born. See Appendix A1 for details of participant backgrounds. The mean age was 25.61 years $(S D=3.16)$. The mean length of stay in Australia at T1 (excluding local students) was 10.0 months $(S D=18.0)$.

\section{Materials}

This study was part of a larger project concerning social networks and the crosscultural adaptation of international students. In the data collection, the demographic questionnaire was followed by a network questionnaire and then an adjustment questionnaire.

Demographic questionnaire. The demographic questionnaire included questions concerning the participants' gender, nationality, religion, date of arrival in Australia, first language, self-assessed English language skills and cohort (A vs. B). The participants' full names were also recorded to reconstruct the complete friendship network. These names were later changed to personal codes.

Network questionnaire. We asked the participants about their friendship networks and study networks (within and without the Bio-business course), characteristics of the members of those networks and the various activities they engaged in with them. The participants were also required to list the names of all students they could recall in their course, together with their age, gender and nationality. Personal names were used to match their identities over different parts of the data, which were subsequently transformed into codes. The participants were then asked to indicate all students whom they considered 
friends, those they studied with and those they engaged in certain activities with. In the present study, only the data on friendship networks were analysed.

Adjustment questionnaire. This questionnaire assessed the participants' psychological adjustment and sociocultural adjustment. To measure psychological adjustment, six items adapted from the International Students Adjustment Strain (Crano \& Crano, 1993)'I feel that I should never have come to Australia' and 'I frequently cry or feel depressed') were rated on a five-point scale $(1=$ it describes me very well, $5=$ it does not describe me at all). The scores were averaged. Higher scores indicated higher levels of psychological adjustment. The scale was found to be highly reliable at all time points $\left(\alpha_{1}=\right.$ $\left..88, \alpha_{2}=.87, \alpha_{3}=84\right)$.

To measure sociocultural adjustment, Ward and Kennedy (1999) sociocultural adaptation scale with 29 items was used. The participants used a five-point rating scale $(1=$ extreme difficulty, $5=$ no difficulty $)$ to indicate their level of difficulty with various aspects of social life in Australia, including making friends, dealing with bureaucracy and understanding ethnic or cultural differences. The scores were averaged, and higher values indicated higher levels of sociocultural adjustment. The scale had excellent internal consistency at all time points $\left(\alpha_{1}=.94, \alpha_{2}=.95, \alpha_{3}=96\right)$. We also assessed the participants' beliefs about Australians and local knowledge, but these responses were not analysed in this study.

\section{Analytic Strategy}

A Statistical Modeling Framework for Longitudinal Network Data (the Rsiena software, Ripley et al., 2018) was used to analyse data. The four hypotheses were tested by using the following parameters. A significant positive parameter for homophily psychological adjustment would support Hypothesis 1 that predicted the effect of homophily based on psychological adjustment in friend selection; a significant positive parameter for absolute 
difference sociocultural adjustment would support Hypothesis 2 that predicted heterophily based on sociocultural adjustment in friend selection; and significant parameters for contagion of psychological adjustment and contagion of sociocultural adjustment would support Hypotheses 3 and 4, respectively.

We also tested several control variables for endogenous and exogenous effects. See Table 1 for a complete list of these network effects and their definitions. For endogenous effects (network processes), we controlled for outdegree, reciprocity, transitive triplets, transitive reciprocated triplets, indegree-popularity, outdegree-popularity, outdegreeactivity, and outdegree-trunc(1). Both outdegree and reciprocity are the basic effects of the network, so they both needed to be included in any network modelling (Snijders et al., 2010). Transitive triplets and transitive reciprocated triplets were included to control for the local structures in friendship network (Block, 2015). The remaining effects were added to improve the goodness of fit of the model (Lospinoso \& Snijders, 2019).

For exogenous effects (individual attributes), we controlled (1) students' region of origin, (2) local versus international status, (3) student cohort and (4) gender. Region was dichotomised as South Asia (i.e., students from India, Nepal, Pakistan, and Sri Lanka) versus non-South Asia for statistical power consideration (Rienties \& Nolan, 2014) and due to South Asians being the majority in the course. Region was controlled for because past studies have indicated that students' regions of origin can influence adjustment (e.g., Sam, 2001), and thus it was important to separate the homophily effect based on region from that based on adjustment. Local vs international students was controlled for due to tendency for local students to be better adjusted than internationals and to segregate themselves in friendship networks (Brown, 2009; Khawaja \& Dempsey, 2008). Cohort was controlled because the two groups commenced the course at different times and thus might have differed in their degrees of adjustment and network development at T1, with potential influence on their 
network selection (Brown, 2009). For gender, evidence suggested both a tendency to form a friendship with others of the same gender (e.g., Kiuru, Burk, Laursen, Nurmi, \& SalmelaAro, 2012; Kiuru, Burk, Laursen, Salmela-Aro, \& Nurmi, 2010) and gender differences in adjustment (Senyshyn, Warford, \& Zhan, 2000).

The scales of psychological adjustment and sociocultural adjustment were analysed together to control them for each other. Missing data were treated in the following conventional manner: the missing network data were set to 0 for students who did not participate at all (they were assumed to have no ties); for those who had missing data at either $\mathrm{T} 2$ or $\mathrm{T} 3$, the missing values were replaced by the last observed value. For behaviours, a similar principle was applied. Missing covariates were replaced by its global mean.

For estimation of the parameters we use the method of moments (Snijders, 2009). Rsiena generates a sequence of changes in-between observations by simulating the actors' decisions according to the model-specifications. The model parameters are calibrated by matching features of the predicted data to the observed data, and for the fitted model this generated data is also used to assess goodness of fit (Lospinoso \& Snijders, 2019). If a parameter is not significantly different from zero it means that the corresponding effect plays no role in how the actors make their decisions. If the fitted model replicates all features of the observations, then the fitted model is sufficient for explaining the data. The rates are not part of the discrete-choice part of the model but correspond to the number of changes, per actor, in-between observations. If, for example, the number of observed changes in the network ties is 2 on average across the actors, then the rate per actor is estimated to be at least 2 (both probably more). 


\section{Results}

\section{Descriptive Statistics}

The participants were moderately well-adjusted, which is consistent with previous findings in similar Australian contexts (Kashima et al., 2017; Rosenthal, Russell, \& Thomson, 2007). Both psychological adjustment $\left(M_{\mathrm{T} 1}=4.02, S D_{\mathrm{T} 1}=1.04 ; M_{\mathrm{T} 2}=4.00\right.$, $\left.S D_{\mathrm{T} 2}=0.92 ; M_{\mathrm{T} 3}=3.93, S D_{\mathrm{T} 3}=0.97\right)$ and sociocultural adjustment $\left(M_{\mathrm{T} 1}=3.78, S D_{\mathrm{T} 1}=0.69 ;\right.$ $\left.M_{\mathrm{T} 2}=3.92, S D_{\mathrm{T} 2}=0.66 ; M_{\mathrm{T} 3}=3.84, S D_{\mathrm{T} 3}=0.75\right)$ were stable over the three time-points. The indices of the network structure suggested that the friendship networks were also stable, with no significant change in the tendency for actors to nominate others (i.e., average outdegree: $\left.M_{\mathrm{T} 1}=7.70, S D_{\mathrm{T} 1}=3.55 ; M_{\mathrm{T} 2}=7.96, S D_{\mathrm{T} 2}=4.13 ; M_{\mathrm{T} 3}=7.39, S D_{\mathrm{T} 3}=4.44\right)$.

To test whether it was appropriate to continue with SAOM, the Quadratic Assignment Procedure (QAP) was deployed to examine the correlation between friendship networks at different time points (T1, T2 and T3). ${ }^{2}$ We found significant correlations between T1 and T2 (Jaccard index $=.41, p<.001)$ and between T2 and T3 (Jaccard index $=.46, p<.001)$. Since the Jaccard index values were higher than .20, it was appropriate to continue with SAOM (Ripley et al., 2018).

\section{Hypothesis Testing}

All effects included in the model are reported in Table 1. Here we will report on the outcomes of the hypotheses, followed by a report of the additional effects that were controlled for and were found to be significant.

The parameter for homophily psychological adjustment was positive and significant. The closer the level of psychological adjustment between the actor and another student was, the more likely the actor was to select the latter as a friend. Thus, Hypothesis 1 was supported. The parameter for absolute difference sociocultural adjustment was also positive and significant. The data pattern suggested that the more different the level of sociocultural 
adjustment was between them, the more likely the actor was to select the other. Thus, the results corroborated with Hypothesis 2.

Turning to the models of social influence, the expected effects of contagion of both psychological and sociocultural adjustment were non-significant. Thus, in contrast to the support gained by the two social selection models, the social influence models of contagion gained little support. Hypotheses 3 and 4 were rejected. All results can be seen in Table 1 .

\section{Additional Results}

In addition to the effects hypothesised, we also found several significant control variables which showed important information about the friendship network dynamics. Ego sociocultural adjustment was significant and negative, suggesting that students who were better-adjusted, socioculturally, tended to withdraw from friendships more in the course over time.

Among the endogenous network processes that were in the model, a significant positive parameter for reciprocity was found, indicating a tendency for students to choose others who have already nominated them. The parameter for transitive triplets was positive and indicated two common tendencies in affiliative social networks: to mutually affirm social relationships and to form friendships with friends-of-friends. The parameter for transitive reciprocated triplets was negative and significant, an effect often found in dynamic social networks (Block, 2015). In combination, this means that an actor tends to make friends with their friend's friend, but the target of this friendship formation tends not to reciprocate a friendship tie. According to Block (2015), this is consistent with Heider's (1958) balance theory. Outdegree popularity was also negative and significant, indicating that students who nominated more friends tended to be avoided more (i.e., less popular). This suggests a global hierarchy in friendship nominations, so that people tend to nominate people with higher status than themselves (Müller, Grund, \& Koskinen, 2018). The parameter for outdegree-trunc was 
negative and significant, meaning that there was a tendency for some students to nominate no friend over time, suggesting that some students completely withdrew from social activities in the course. Finally, we found Outdegree to be negative and significant, which meant that in balance, any two students were less likely to nominate one another as friends, as found in previous studies (e.g., Block, Heathcote, \& Burnett Heyes, 2018).

As for the processes that involved individual attributes, two effects relating to homophily were significant. A positive parameter for homophily South Asia suggested a tendency for international students to form friendships with peers from the same region, and also, a positive parameter for homophily cohort showed that students tended to form friendships with peers from the same cohort. Furthermore, alter cohort was negative and significant, which indicated that students from cohort A, the smaller of the two groups, were less likely to be selected as friends over time.

\section{Follow-Up Analysis}

Because several homophily effects were significant in the model, it seemed important to follow them up to clarify the nature of these effects. One question concerned whether the homophily was driven more by the selection of students with similar attribute(s) or by deselection of dissimilar ones. To examine this question, we added two new parameters for each of the previously significant homophily effects: friendship similarity selection and friendship dissimilarity deselection. This operation effectively splits each homophily effect in the initial model (i.e., Model 1) in two: previously, a homophily effect was non-directional (i.e., the more similar, the more likely to form a tie) but now, effects in two different directions are also tested. The new model (Model 2) included six new parameters (similarity selection for psychological adjustment, South Asia, cohort and dissimilarity deselection for those same variables) and kept all other effects as controls. 
The outcome for the new parameters depended on the type of homophily (see Table 1 for details). For psychological adjustment, there was a significant and positive effect of dissimilarity deselection, underscoring the tendency for students to abort ties with others who were dissimilar in level of adjustment. There was no evidence for similarity selection. The same pattern was found for cohort, where students tend to abort their ties with students in the different cohort. In contrast, for region, there was a significant and positive effect of similarity section only, suggesting that students selected others from the same region rather than aborting ties with those from different regions.

\section{Discussion}

The study found support for the two social selection hypotheses. The prediction that students tend to make friends with others in the course who are similar in their levels of psychological adjustment was supported. They may have felt more comfortable interacting with students who had similar rather than different levels of psychological adjustment. The follow-up analysis also suggested that the tendency was more likely due to deselection than selection. Rather than actively seeking out friends with a similar level of psychological adjustment, students tended to dissolve ties when the level of psychological adjustment seemed different. As psychological adjustment is not necessarily apparent, a degree of relational closeness may be required before friends recognise their dissimilarity in adjustment level (Rose, 2002; Schneider, Schimmack, Petrican, \& Walker, 2010). When a discrepancy is noticed, the relationship may weaken, possibly due to difficulty in building empathy (Kulik \& Mahler, 2000; Rook, Pietromonaco, \& Lewis, 1994), frustration with each other (Workum, Scholte, Cillessen, Lodder, \& Giletta, 2013), fear of contamination by the better-adjusted partner (Schaefer et al., 2011) or due to a lack of common interests.

The second prediction that students in the same course tend to befriend those who differ in their level of sociocultural adjustment was also supported. This tendency may be 
associated with the complementarity of skills (Gallagher \& Robins, 2015; Rivera et al., 2010). For instance, those who have greater skills in negotiating with local people may take the role of representative, whereas those with fewer skills in the area may return their loyalty. This result might also be connected with our secondary finding, which indicated that students with better sociocultural adjustment tend to withdraw from friendship in the classroom. This tendency may be due to those students being more capable of fitting in with the networks outside the course compared to their peers with lower sociocultural skills. The withdrawal of better-skilled students from the friendship networks would limit the pool of students with better sociocultural adjustment, forcing these students to make friends with those who were less adjusted socioculturally. The less adjusted students, in contrast, may turn to classmates with better sociocultural adjustment as the latter would be able to provide them with the necessary resources to adjust (Kudo \& Simkin, 2003; Stier, 2009).

The third and fourth hypotheses, concerning social influence, or contagion effects, were not supported. A potential explanation for these results is that influence processes such as contagion occur gradually (Rosenquist et al., 2011), and the duration of our study was too short. Rosenquist et al. (2011) study on social contagion of depression took longitudinal data that span for 20 years. Also, it may be that the strength of friendship ties in the course was too weak for contagion to occur. Elmer et al. (2017) found that students that lived in a graduate house community influence the subjective wellbeing of their friends only if they have strong friendship ties with their friends. Even so, the effect of the social influence that they found was marginal. Evidence that may support the weakness of friendship connection between students in this study is the dissolution of friendship once their cohort was separated. Once there was a lack of direct contact between students of the different cohort, their friendship connections tend to end. 
Another homophily effect that we found was region-based friendship or South Asian homophily. This result seems understandable given the characteristics of the group. First, a large proportion of the participants were from South Asia (India), lending them an opportunity to strengthen their ethnic identity (Kim, 2001). Also, the course involved only a small proportion of local students, thus diminishing the pressure to conform to the local culture or to mix with local students.

Our results also found a strong tendency of forming local hierarchy which can be seen from positive parameter in transitive triplets and negative parameter in transitive reciprocated triplets. Previous studies had found similar "inequality" among friends, but those studies were mainly done among children and adolescent (e.g., Dijkstra, Cillessen, \& Borch, 2013). Our study and that of Elmer et al. (2017) provided evidence that such a pattern of friendship was also common among adults.

\section{Limitations}

There are several methodological limitations, such as generalisability, statistical power, and missing data that are unique to network research. In generalising the current results to a wider context, caution is required. First, whole network analyses attempted here aimed to understand the social processes and the properties of a networked social system in question, not necessarily the general characteristics of a general population encompassing all international students. This study should, therefore, be understood as a case study of one networked social system and its outcomes are not necessarily generalisable.

With respect to statistical power, small network size is not unusual for social network analysis (e.g., Block, Heathcote, et al., 2018; Ellwardt, Steglich, \& Wittek, 2012). However, the statistical power of longitudinal whole-network studies is not directly equivalent to that of conventional studies (Stadtfeld, Snijders, Steglich, \& van Duijn, 2018). Network studies deal not only with individual cases but their interconnected and dynamic nature over time. For 
instance, for the social selection component of the SAOM in this study, the unit of analysis is the number of potential relationships between participants over two periods of time; thus, the total number of potential relations is $38 \times(38-1) \times 2=2812$ relations. For the social influence component, however, the calculation formula is closer to the common understanding of sample size: i.e., the number of participants multiplied by the number of time points minus one. For our case, this is $38 \times(3-1)=76$. In should be noted that the number of units of analysis is not the same as sample size in network models (see Block, Koskinen, Hollway, Steglich, \& Stadtfeld, 2018; Koskinen, Wang, Robins, \& Pattison, 2018; Krivitsky \& Kolaczyk, 2015). Because of these differences, some researchers have commented that statistical power for social influence portion of SAOM may be relatively low when compared to its social selection component (Stadtfeld et al., 2018). We acknowledge this as a limitation of our study. Yet, given the interdependent dynamic nature of the data, statistical power cannot be increased simply be adding more individual cases; rather entire networks (i.e., additional cohorts of students, following for example the paradigm of Snijders and Baerveldt (2003) later developed in Snijders and Koskinen (2012)) must be added - often infeasible in many studies, such as this one. As such, statistical power must be addressed during the study design phase by taking into consideration not only the number of actors, but also the scaling of the behavioural outcome variable, the number of data collection waves, or the maximum number of network nominations that a participant can make (Stadtfeld et al., 2018). For future research, we urge pre-attention to maximizing statistical power, especially for large funded studies in which the main research questions pertain to questions of social influence. A further methodological issue is the impact of missing data on statistical inference, as produced through attrition and participant refusals. Given the interlocking, interdependent nature of network data, not observing one network tie can change our conclusions about the structure of the network that we have observed (Koskinen, Robins, Wang, \& Pattison, 2013). 
Despite some advances in methods for identifying and compensating for its effects (Bright, Koskinen, \& Malm, 2019; Hipp, Wang, Butts, Jose, \& Lakon, 2015; Koskinen et al., 2013; Krause, Huisman, Steglich, \& Snijders, 2018), it remains the case that whole-network analyses ideally should rely on census-like data collections, with an ideal participation rate of $100 \%$. However, achieving complete participation, while possible in educational research, is nevertheless infrequent, and lower (but still quite high) participation rates, such as the $70 \%$ rate in this study, are widely tolerated (e.g., Kiuru et al., 2017; Lusher, 2011).

Concerning participant characteristics, the majority of international students in this course were from South Asia, and only a few were domestic students. The dynamics of the students in the course may have been different if local students had been a majority or if there had been a balance in the numbers of international and local students. In courses with better balance, international students would, potentially, have more accesses to local students whom they can befriend. At the same time, the local students would have more options to choose from in befriending fellow locals or internationals. In such circumstances, the dynamics of students are likely to change (Maundeni, 2001). As a future direction, the whole networks of different compositions could be compared to answer questions such as which composition can facilitate newcomers' social, psychological, and academic outcomes, or achieve intercultural integration most effectively, for instance.

\section{Implications and Future Directions}

The present study has provided some valuable contributions to the literature. First, this study showed that adjustment is one of the determining factors in the formation of friendships, whereas, in most cross-cultural adaptation research, friendships were often treated as the driving force that helps determine psychological and sociocultural adjustment (e.g., Hendrickson et al., 2011; Kashima \& Loh, 2006). Second, this study provided further evidence that social selection, rather than social influence, was the primary network process 
involving friendship among the tertiary-level international students (Elmer et al., 2017).

Third, this study revealed the difference in the direction of social selection involving psychological and sociocultural adjustment. Students showed their preference in befriending others with similar levels of psychological adjustment but dissimilar levels of sociocultural adjustment. Fourth, in term of regional homophily, this study replicated previous studies in finding the tendency of regional homophily in friendship formation (e.g., Rienties \& Nolan, 2014). This finding clarifies that the regional homophily in friendship formation is unaccounted for by the preference to befriend someone with a similar level of psychological adjustment. Whereas the region-based homophily was based on similarity-selection, the psychological adjustment homophily was driven by the omission of dissimilar other.

From a methodological perspective, SAOM can be used to track changes in (multicultural) networks, alongside changes in individual behaviour, and see if these changes are related to one another, and if they are statistically significant. Previous studies (e.g., Rienties \& Nolan, 2014) have managed to detect certain changes in multicultural classrooms, but they failed to indicate whether the changes were statistically significant. SAOM, therefore, provides acculturation researchers with a new means to study the process of acculturation at the community (group) and individual levels to better understand the dynamic between the two. Whole-network methods, in general, could also be integrated into current university student surveys to help universities understand how international students relate to one another and how those relations affect their well-being and satisfaction and vice versa. It could also be used to study the effectiveness of university programmes that promote intercultural relations, such as mentoring and cultural events.

There are also practical implications for international students, educators and their support providers. First, these results highlight the strong tendency of similarity attraction (homophily) in friendship formation among culturally diverse university students. However, 
it should be questioned whether associating mainly with those similar to oneself is likely to support the best academic and social outcomes in the long term, as well as satisfying international students' oft-stated desire to fit-in to the host environment. International students likely need to encouragement to actively connect with fellow students beyond those similar to themselves, especially in visible attributes such as their regional origin. For instance, interacting with students who have complementary skills to their own and forging friendships with them would be valuable for gaining wider perspectives and increased creativity. To facilitate such interactions among diverse members of the student body, academic and support staff can provide students with a series of opportunities to meet students outside their 'default' group, for example, by randomly assigning domestic and international students to groups that require members to use various sociocultural skills to attain a shared goal. Such programmes, already implemented in some tertiary institutions, indicate positive impacts on students' intergroup attitudes and intercultural competence (Jon, 2013; Mak, Brown, \& Wadey, 2014). Furthermore, we can also identify better-adjusted students and making them part of a structured support program such as the buddy program in order to help the less well-adjusted students. This might help with contagion and skill transfer.

\section{Conclusion}

Similarities in the level of psychological adjustment and differences in sociocultural adjustment were found to be the key factors in friendship formation within the postgraduate programme that involved a large proportion of international students. Based on the results of this study, we speculate that students who flourish tend to enjoy the company of peers who flourish, whereas those who suffer challenges may commiserate with peers who also suffer challenges. Thus, friendships form through a process of homophily (similarity attraction) 
based on psychological adjustment. Conversely, we found no evidence to suggest that psychological adjustment is socially transmitted through friendship ties.

This study adds to a handful of previous research that found wellbeing-based homophily to be important in the development of friendships (Elmer et al., 2017). In our study, however, we have taken a further step to clarify that heterophily based on sociocultural adjustment also is a route to the development of friendships among international students. Our findings provide further evidence that relationships are not only based on strict homophily or heterophily but can be based on a combination of the two (Rivera et al., 2010). 


\section{Footnotes}

${ }^{1}$ One of the underlying assumptions in SAOM is that the network and behaviour evolve in continuous time through incremental changes to the state of the system. These incremental changes are determined by the choices made by the actors and modelled using standard discrete-choice models or conditional logit models (Snijders et al., 2010). When a change to the network or the actor attributes is considered by actors, they base their decision on the current state of the network and the attributes. This means that these changes are following a Markov process, that is, the current state of the network determines the probability of the direction of the network evolution. SAOM has a well-established set of estimation routines for estimating the parameters of this process from panel network data as well as a goodness-of-fit routine for assessing whether a fitted model is sufficient for explaining key features of the observed data (Lospinoso \& Snijders, 2019).

${ }^{2}$ The QAP correlates the two matrices of friendship networks by reshaping them into two long columns and calculating an ordinary measure of statistical association, such as the Jaccard Index (Borgatti, Everett, \& Johnson, 2013) 


\section{References}

Australian Government Department of Education and Training [AGDET]. (2015). International student survey 2014: Overview report.

Block, P. (2015). Reciprocity, transitivity, and the mysterious three-cycle. Social Networks, 40, 163-173. https://doi.org/10.1016/j.socnet.2014.10.005

Block, P., Heathcote, L. C., \& Burnett Heyes, S. (2018). Social interaction and pain: An arctic expedition. Soc Sci Med, 196, 47-55. https://doi.org/10.1016/j.socscimed.2017.10.028

Block, P., Koskinen, J., Hollway, J., Steglich, C., \& Stadtfeld, C. (2018). Change we can believe in: Comparing longitudinal network models on consistency, interpretability and predictive power. Social Networks, 52, 180-191. https://doi.org/10.1016/j.socnet.2017.08.001

Bochner, S., McLeod, B. M., \& Lin, A. (1977). Friendship patterns of overseas students: A functional model. International Journal of Psychology, 12(4), 277-294.

Borgatti, S. P., Everett, M. G., \& Johnson, J. C. (2013). Analyzing social networks. London: SAGE

Bright, D., Koskinen, J., \& Malm, A. (2019). Illicit network dynamics: The formation and evolution of a drug trafficking network. Journal of Quantitative Criminology, 35(2), 237-258. doi:10.1007/s10940-018-9379-8

Brown, L. (2009). An ethnographic study of the friendship patterns of international students in england: An attempt to recreate home through conational interaction. International Journal of Educational Research, 48(3), 184-193.

Carp, F. M., \& Carp, A. (1983). Structural stability of well-being factors across age and gender, and development of scales of well-being unbiased for age and gender. Journal of Gerontology, 38(5), 572-581. 
Cheadle, J. E., \& Goosby, B. J. (2012). The small-school friendship dynamics of adolescent depressive symptoms. Society and Mental Health, 2(2), 99-119.

Cotterall, S. (2011). Identity and learner autonomy in doctoral study: International students' experiences in an australian university. In (pp. 57-72): Hong Kong University Press.

Crano, S. L., \& Crano, W. D. (1993). A measure of adjustment strain in international students. Journal of Cross-Cultural Psychology, 24(3), 267-283.

Dalglish, C. L., \& Chan, A. O. (2005). Expectations and reality-international student reflections on studying in australia. Paper presented at the Australian International Education Conference 2005, Gold Coast, Australia. https://eprints.qut.edu.au/2337/

Dijkstra, J. K., Cillessen, A. H. N., \& Borch, C. (2013). Popularity and adolescent friendship networks: Selection and influence dynamics. Developmental Psychology, 49(7), 12421252. doi:10.1037/a0030098

Dokuka, S., Valeeva, D., \& Yudkevich, M. (2015). The diffusion of academic achievements: Social selection and influence in student networks. Higher School of Economics Research Paper No. WP BRP 65/SOC/2015. http://dx.doi.org/10.2139/ssrn.2658031

Ellwardt, L., Steglich, C., \& Wittek, R. (2012). The co-evolution of gossip and friendship in workplace social networks. Social Networks, 34(4), 623-633. https://doi.org/10.1016/j.socnet.2012.07.002

Elmer, T., Boda, Z., \& Stadtfeld, C. (2017). The co-evolution of emotional well-being with weak and strong friendship ties. Network Science, 5(03), 278-307.

Ferguson, H., \& Sherrell, H. (2019). Overseas students in australian higher education: A quick guide. Retrieved from https://www.aph.gov.au/About_Parliament/Parliamentary_Departments/Parliamentary _Library/pubs/rp/rp1819/Quick_Guides/OverseasStudents 
Fowler, J. H., \& Christakis, N. A. (2008). Dynamic spread of happiness in a large social network: Longitudinal analysis over 20 years in the framingham heart study. $B M J$, 337(dec04 2), a2338-a2338.

Furnham, A., \& Alibhai, N. (1985). The friendship networks of foreign students: A replication and extension of the functional model. International Journal of Psychology, 20(3-4), 709-722.

Gallagher, H. C. (2013). Willingness to communicate and cross-cultural adaptation: L2 communication and acculturative stress as transaction. Applied Linguistics, 34(1), 5373. doi:10.1093/applin/ams023

Gallagher, H. C., \& Robins, G. (2015). Network statistical models for language learning contexts: Exponential random graph models and willingness to communicate. Language Learning, 65(4), 929-962. doi:10.1111/lang.12130

Heider, F. (1958). The psychology of interpersonal relations. NewJersey: Lawrence Erlbaum Associates Inc.

Hendrickson, B., Rosen, D., \& Aune, R. K. (2011). An analysis of friendship networks, social connectedness, homesickness, and satisfaction levels of international students. International Journal of Intercultural Relations, 35(3), 281-295.

Hipp, J. R., Wang, C., Butts, C. T., Jose, R., \& Lakon, C. M. (2015). Research note: The consequences of different methods for handling missing network data in stochastic actor based models. Social Networks, 41, 56-71. https://doi.org/10.1016/j.socnet.2014.12.004

Hirai, R., Frazier, P., \& Syed, M. (2015). Psychological and sociocultural adjustment of firstyear international students: Trajectories and predictors. Journal of Counseling Psychology, 62(3), 438-452. doi:10.1037/cou0000085 
Jaccard, J., Blanton, H., \& Dodge, T. (2005). Peer influences on risk behavior: An analysis of the effects of a close friend. Developmental Psychology, 41(1), 135-147. doi:10.1037/0012-1649.41.1.135

Jon, J.-E. (2013). Realizing internationalization at home in korean higher education:Promoting domestic students' interaction with international students and intercultural competence. Journal of Studies in International Education, 17(4), 455470. doi:10.1177/1028315312468329

Kashima, E. S., Greiner, T., Sadewo, G., Ampuni, S., Helou, L., Nguyen, V. A., . . Kaspar, K. (2017). Open- and closed-mindedness in cross-cultural adaptation: The roles of mindfulness and need for cognitive closure. International Journal of Intercultural Relations, 59, 31-42. doi:https://doi.org/10.1016/j.ijintrel.2017.05.001

Kashima, E. S., \& Loh, E. (2006). International students' acculturation: Effects of international, conational, and local ties and need for closure. International Journal of Intercultural Relations, 30(4), 471-485. doi:10.1016/j.ijintrel.2005.12.003

Khawaja, N. G., \& Dempsey, J. (2008). A comparison of international and domestic tertiary students in australia. Australian Journal of Guidance and Counselling, 18(01), 30-46.

Kim, Y. Y. (2001). Becoming intercultural: An integrative theory of communication and cross-cultural adaptation. Retrieved from http://sk.sagepub.com/books/becomingintercultural doi:10.4135/9781452233253

Kiuru, N., Burk, W. J., Laursen, B., Nurmi, J.-E., \& Salmela-Aro, K. (2012). Is depression contagious? A test of alternative peer socialization mechanisms of depressive symptoms in adolescent peer networks. Journal of Adolescent Health, 50(3), 250-255.

Kiuru, N., Burk, W. J., Laursen, B., Salmela-Aro, K., \& Nurmi, J.-E. (2010). Pressure to drink but not to smoke: Disentangling selection and socialization in adolescent peer 
networks and peer groups. Journal of Adolescence, 33(6), 801-812.

https://doi.org/10.1016/j.adolescence.2010.07.006

Kiuru, N., DeLay, D., Laursen, B., Burk, W. J., Lerkkanen, M.-K., Poikkeus, A.-M., \& Nurmi, J.-E. (2017). Peer selection and influence on children's reading skills in early primary grades: A social network approach. Reading and Writing, 30(7), 1473-1500. doi:10.1007/s11145-017-9733-5

Koskinen, J., Robins, G. L., Wang, P., \& Pattison, P. E. (2013). Bayesian analysis for partially observed network data, missing ties, attributes and actors. Social Networks, 35(4), 514-527. https://doi.org/10.1016/j.socnet.2013.07.003

Koskinen, J., Wang, P., Robins, G., \& Pattison, P. (2018). Outliers and influential observations in exponential random graph models. Psychometrika, 83(4), 809-830. doi:10.1007/s11336-018-9635-8

Krause, R. W., Huisman, M., Steglich, C., \& Snijders, T. A. B. (2018, 28-31 Aug. 2018). Missing network data a comparison of different imputation methods. Paper presented at the 2018 IEEE/ACM International Conference on Advances in Social Networks Analysis and Mining (ASONAM).

Krivitsky, P. N., \& Kolaczyk, E. D. (2015). On the question of effective sample size in network modeling: An asymptotic inquiry. Statist. Sci., 30(2), 184-198. doi:10.1214/14-STS502

Kudo, K., \& Simkin, K. A. (2003). Intercultural friendship formation: The case of japanese students at an australian university. Journal of Intercultural Studies, 24(2), 91-114.

Kulik, J. A., \& Mahler, H. I. M. (2000). Social comparison, affiliation, and emotional contagion under threat. In S. J. \& W. L. (Eds.), Handbook of social comparison (pp. 295-319). New York: Plenum. 
Lospinoso, J., \& Snijders, T. A. (2019). Goodness of fit for stochastic actor-oriented models. Methodological Innovations, 12(3), 2059799119884282. doi:10.1177/2059799119884282

Lusher, D. (2011). Masculinity, educational achievement and social status: A social network analysis. Gender and Education, 23(6), 655-675. doi:10.1080/09540253.2010.527825

Lusher, D., Koskinen, J., \& Robins, G. (2013). Exponential random graph models for social networks: Theory, methods, and applications. New York: Cambridge University Press.

Mak, A. S., Brown, P. M., \& Wadey, D. (2014). Contact and attitudes toward international students in australia:Intergroup anxiety and intercultural communication emotions as mediators. Journal of Cross-Cultural Psychology, 45(3), 491-504. doi:10.1177/0022022113509883

Marsden, P., \& Friedkin, N. (1994). Network studies of social influence. In S. Wasserman \& J. Galaskiewicz (Eds.), Advances in social network analysis: Research in the social and behavioral sciences (pp. 3-25). California: SAGE Publications, Inc.

Maundeni, T. (2001). The role of social networks in the adjustment of african students to british society: Students' perceptions. Race Ethnicity and Education, 4(3), 253-276.

McPherson, M., Smith-Lovin, L., \& Cook, J. M. (2001). Birds of a feather: Homophily in social networks. Annual Review of Sociology, 27(1), 415-444.

Moody, J. (2004). The structure of a social science collaboration network: Disciplinary cohesion from 1963 to 1999. American Sociological Review, 69(2), 213-238. doi:10.1177/000312240406900204

Müller, T. S., Grund, T. U., \& Koskinen, J. H. (2018). Residential segregation and 'ethnic flight'vs. 'Ethnic avoidance'in sweden. European Sociological Review, 34(3), 268285. 
Ozer, S. (2015). Predictors of international students' psychological and sociocultural adjustment to the context of reception while studying at aarhus university, denmark. Scandinavian Journal of Psychology, 56(6), 717-725. doi:10.1111/sjop.12258

Parker, J. G., \& Asher, S. R. (1993). Friendship and friendship quality in middle childhood: Links with peer group acceptance and feelings of loneliness and social dissatisfaction. Developmental Psychology, 29(4), 611-621. doi:10.1037/0012-1649.29.4.611

Rienties, B., \& Nolan, E.-M. (2014). Understanding friendship and learning networks of international and host students using longitudinal social network analysis. International Journal of Intercultural Relations, 41, 165-180.

Ripley, R. M., Snijders, T. A. B., Boda, Z., Vörös, A., \& Preciado, P. (2018). Manual for rsiena. In. Oxford: Oxford University.

Rivera, M. T., Soderstrom, S. B., \& Uzzi, B. (2010). Dynamics of dyads in social networks: Assortative, relational, and proximity mechanisms. Annual Review of Sociology, 36(1), 91-115. doi:10.1146/annurev.soc.34.040507.134743

Robins, G. (2015). Doing social network research: Network-based research design for social scientists. London: SAGE.

Robins, G., Elliott, P., \& Pattison, P. (2001). Network models for social selection processes. Social Networks, 23(1), 1-30.

Rook, K. S., Pietromonaco, P. R., \& Lewis, M. A. (1994). When are dysphoric individuals distressing to others and vice versa? Effects of friendship, similarity, and interaction task. Journal of Personality and Social Psychology, 67(3), 548-559. doi:10.1037/0022-3514.67.3.548

Rose, A. J. (2002). Co-rumination in the friendships of girls and boys. Child Development, 73(6), 1830-1843. doi:10.1111/1467-8624.00509 
Rosenquist, J. N., Fowler, J. H., \& Christakis, N. A. (2011). Social network determinants of depression. Molecular Psychiatry, 16(3), 273-281.

Rosenthal, D. A., Russell, J., \& Thomson, G. (2006). A growing experience: The health \& well-being of international students at the university of melbourne. Melbourne: University of Melbourne.

Rosenthal, D. A., Russell, J., \& Thomson, G. (2007). Social connectedness among international students at an australian university. Social Indicators Research, 84(1), $71-82$.

Sam, D. L. (2001). Satisfaction with life among international students: An exploratory study. Social Indicators Research, 53(3), 315-337.

Sawir, E., Marginson, S., Deumert, A., Nyland, C., \& Ramia, G. (2008). Loneliness and international students: An australian study. Journal of Studies in International Education, 12(2), 148-180.

Schaefer, D. R., Kornienko, O., \& Fox, A. M. (2011). Misery does not love company: Network selection mechanisms and depression homophily. American Sociological Review, 76(5), 764-785.

Schneider, L., Schimmack, U., Petrican, R., \& Walker, S. (2010). Acquaintanceship length as a moderator of self-informant agreement in life-satisfaction ratings. Journal of Research in Personality, 44(1), 146-150. doi:10.1016/j.jrp.2009.11.004

Selfhout, M., Burk, W., Branje, S., Denissen, J., van Aken, M., \& Meeus, W. (2010). Emerging late adolescent friendship networks and big five personality traits: A social network approach. Journal of Personality, 78(2), 509-538.

Senyshyn, R., Warford, M., \& Zhan, J. (2000). Issues of adjustment to higher education: International students' perspectives. International Education, 30(1), 17-35. 
Sherry, M., Thomas, P., \& Chui, W. H. (2010). International students: A vulnerable student population. Higher Education, 60(1), 33-46.

Snijders, T. A. B. (2009). Network analysis, longitudinal methods of. In R. A. Meyers (Ed.), Encyclopedia of complexity and systems science (pp. 5998-6013). New York, NY: Springer New York.

Snijders, T. A. B., \& Baerveldt, C. (2003). A multilevel network study of the effects of delinquent behavior on friendship evolution. The Journal of Mathematical Sociology, 27(2-3), 123-151. doi:10.1080/00222500305892

Snijders, T. A. B., \& Koskinen, J. (2012). Multilevel longitudinal analysis of social networks. Paper presented at the 8th UKSNA Conference, Bristol.

Snijders, T. A. B., van de Bunt, G. G., \& Steglich, C. E. G. (2010). Introduction to stochastic actor-based models for network dynamics. Social Networks, 32(1), 44-60.

Stadtfeld, C., Snijders, T. A. B., Steglich, C., \& van Duijn, M. (2018). Statistical power in longitudinal network studies. Sociological Methods \& Research, $0(0)$. doi:10.1177/0049124118769113

Stier, J. (2009). Intercultural communication and intercultural competence. Journal of Intercultural Communication(11), 1-12.

Ward, C., \& Kennedy, A. (1993). Where's the "culture" in cross-cultural transition?: Comparative studies of sojourner adjustment. Journal of Cross-Cultural Psychology, 24(2), 221-249.

Ward, C., \& Kennedy, A. (1999). The measurement of sociocultural adaptation. International Journal of Intercultural Relations, 23(4), 659-677.

Ward, C., Okura, Y., Kennedy, A., \& Kojima, T. (1998). The u-curve on trial: A longitudinal study of psychological and sociocultural adjustment during cross-cultural transition. 
International Journal of Intercultural Relations, 22(3), 277-291. doi:10.1016/S01471767(98)00008-X

Wimmer, A., \& Lewis, K. (2010). Beyond and below racial homophily: Erg models of a friendship network documented on facebook. American Journal of Sociology, 116(2), 583-642. doi:10.1086/653658

Workum, N., Scholte, R. H. J., Cillessen, A. H. N., Lodder, G. M. A., \& Giletta, M. (2013). Selection, deselection, and socialization processes of happiness in adolescent friendship networks. Journal of Research on Adolescence, 23(3), 563-573. doi:10.1111/jora.12035 
Table 1

Complete Stochastic Actor Based Model for Psychological and Sociocultural Adjustment: Unstandardised Coefficients and Standard Errors

\begin{tabular}{|c|c|c|c|c|c|}
\hline & \multicolumn{2}{|c|}{ Model 1} & \multirow{2}{*}{\multicolumn{2}{|c|}{ Model 2}} & \multirow[t]{2}{*}{ Result Interpretation } \\
\hline & $\mathrm{PE}$ & $S E$ & & & \\
\hline \multicolumn{6}{|l|}{ Psychological Adjustment Selection } \\
\hline $\begin{array}{l}\text { Homophily Psychological } \\
\text { Adjustment (H1) }\end{array}$ & $1.21 *$ & $(0.47)$ & & & $\begin{array}{l}\text { Students were more likely to befriend another student whose level of } \\
\text { psychological adjustment was more similar to themselves }\end{array}$ \\
\hline $\begin{array}{l}\text { Friendship Dissimilarity } \\
\text { Deselection (H1) }\end{array}$ & & & $2.01 * *$ & $(0.75)$ & $\begin{array}{l}\text { Students were more likely to dissolve their friendship tie with someone } \\
\text { more dissimilar to themselves in the level of psychological adjustment }\end{array}$ \\
\hline $\begin{array}{l}\text { Friendship Similarity Selection } \\
\text { (H1) }\end{array}$ & & & 0.54 & $(0.71)$ & $\begin{array}{l}\text { Students were more likely to select as a friend someone who was more } \\
\text { similar to themselves in the level of psychological adjustment. }\end{array}$ \\
\hline Alter Psychological Adjustment & 0.13 & $(0.09)$ & 0.13 & $(0.08)$ & $\begin{array}{l}\text { Students who differed in their levels of sociocultural adjustment were } \\
\text { equally likely to be nominated as friends }\end{array}$ \\
\hline Ego Psychological Adjustment & 0.11 & $(0.09)$ & 0.11 & $(0.09)$ & $\begin{array}{l}\text { Students who differed in their levels of psychological adjustment were } \\
\text { equally likely to nominate others as friends (activity) }\end{array}$ \\
\hline \multicolumn{6}{|l|}{ Sociocultural Adjustment Selection } \\
\hline $\begin{array}{l}\text { Absolute Difference } \\
\text { Sociocultural Adjustment (H2) }\end{array}$ & $0.29 *$ & $(0.14)$ & $0.29+$ & $(0.16)$ & $\begin{array}{l}\text { Students were more likely to befriend another student whose level of } \\
\text { sociocultural adjustment was more dissimilar to their own (heterophily) }\end{array}$ \\
\hline Alter Sociocultural Adjustment & $-0.14 \dagger$ & $(0.08)$ & -0.14 & $(0.09)$ & $\begin{array}{l}\text { Students with a lower (vs. higher) level of sociocultural adjustment were } \\
\text { more likely to be nominated as a friend (marginal in model 1, but non- } \\
\text { significant in model 2) }\end{array}$ \\
\hline Ego Sociocultural Adjustment & $-0.23 *$ & $(0.10)$ & $-0.22 *$ & $(0.11)$ & $\begin{array}{l}\text { Students with a higher level of sociocultural adjustment were less likely } \\
\text { to nominate other as friends (withdrawing) }\end{array}$ \\
\hline \multicolumn{6}{|l|}{ Network Processes } \\
\hline Outdegree & $-1.97 * * *$ & $(0.30)$ & $-1.97 * * *$ & $(0.33)$ & A baseline tendency for friendship ties. \\
\hline Reciprocity & $1.62 * * *$ & $(0.22)$ & $1.65^{* * *}$ & $(0.21)$ & $\begin{array}{l}\text { A person nominated as a friend was highly likely to nominate the same } \\
\text { person as a friend }\end{array}$ \\
\hline Transitive Triplets & $0.25 * * *$ & $(0.04)$ & $0.26^{* * *}$ & $(0.04)$ & Friend of a friend was likely to become friend (clique forming) but \\
\hline Transitive Reciprocated Triplets & $-0.14 * *$ & $(0.05)$ & $-0.16 * *$ & $(0.05)$ & this only stabilises one-sided ties \\
\hline
\end{tabular}


Table 1 (continued)

\begin{tabular}{|c|c|c|c|c|c|}
\hline & \multicolumn{2}{|c|}{ Model 1} & \multicolumn{2}{|c|}{ Model 2} & \multirow{2}{*}{ Result Interpretation } \\
\hline & $\mathrm{PE}$ & $S E$ & $\mathrm{PE}$ & $S E$ & \\
\hline Indegree-Popularity & 0.01 & $(0.02)$ & 0.01 & $(0.02)$ & $\begin{array}{l}\text { There was no tendency for popular students to become more popular } \\
\text { over time }\end{array}$ \\
\hline Outdegree-Popularity & $-0.09 * *$ & $(0.01)$ & $-0.09 * * *$ & $(0.02)$ & $\begin{array}{l}\text { Students who nominated more students as friends were less likely to } \\
\text { receive friendship nominations over time }\end{array}$ \\
\hline Outdegree-Activity & $-0.01+$ & $(0.01)$ & -0.01 & $(0.01)$ & $\begin{array}{l}\text { Students who nominated more students as friends were less likely to } \\
\text { nominate additional friends subsequently (marginal in model } 1 \text { but non- } \\
\text { significant in model 2) }\end{array}$ \\
\hline Outdegree-Trunc(1) & $-2.89 * *$ & $(0.90)$ & $-2.85 * *$ & $(0.98)$ & $\begin{array}{l}\text { There was a baseline tendency against friendship formation } \\
\text { strengthened over time }\end{array}$ \\
\hline \multicolumn{6}{|l|}{ Individual Attributes } \\
\hline Homophily South Asia & $0.30^{* * *}$ & $(0.08)$ & & & $\begin{array}{l}\text { South-Asian (SA) students were more likely to befriend with another } \\
\text { SA student than a non-SA student }\end{array}$ \\
\hline Deselection non-South Asia & & & $0.33+$ & $(0.19)$ & $\begin{array}{l}\text { SA students were more likely to dissolve their friendship tie with a non- } \\
\text { SA students (marginal in model 2) }\end{array}$ \\
\hline Selection South Asia & & & $0.29 *$ & $(0.14)$ & $\begin{array}{l}\text { SA students were more likely to form new friendship ties with another } \\
\text { SA. }\end{array}$ \\
\hline Alter South Asia & -0.12 & $(0.10)$ & -0.13 & $(0.12)$ & $\begin{array}{l}\text { SA students and non-SA students were equally likely to be nominated as } \\
\text { friends (popularity). }\end{array}$ \\
\hline Ego South Asia & -0.14 & $(0.12)$ & -0.14 & $(0.12)$ & $\begin{array}{l}\text { SA students and non-SA students were equally likely to nominate others } \\
\text { as friends (activity). }\end{array}$ \\
\hline Homophily Local & -0.06 & $(0.15)$ & -0.05 & $(0.15)$ & $\begin{array}{l}\text { Local students were no more likely to befriend another local student } \\
\text { than an international student. }\end{array}$ \\
\hline Alter Local & -0.19 & $(0.19)$ & -0.19 & $(0.19)$ & $\begin{array}{l}\text { Local students and international students were equally likely to be } \\
\text { nominated as friends (popularity). }\end{array}$ \\
\hline Ego Local & 0.09 & $(0.21)$ & 0.11 & $(0.21)$ & $\begin{array}{l}\text { Local students and international students were equally likely to } \\
\text { nominate others as friends (activity). }\end{array}$ \\
\hline Homophily Cohort & $0.52 * * *$ & $(0.09)$ & & & $\begin{array}{l}\text { Students were more likely to befriend with another student from the } \\
\text { same cohort. }\end{array}$ \\
\hline Deselection Dissimilar Cohort & & & $0.84 * * *$ & $(0.19)$ & $\begin{array}{l}\text { Students were more likely to dissolve their friendship ties with another } \\
\text { student from a different cohort. }\end{array}$ \\
\hline
\end{tabular}


Table 1 (continued)

\begin{tabular}{|c|c|c|c|c|c|}
\hline \multirow[b]{3}{*}{ Selection Similar Cohort } & \multicolumn{2}{|c|}{ Model 1} & \multicolumn{2}{|c|}{ Model 2} & \multirow[t]{2}{*}{ Result Interpretation } \\
\hline & $\mathrm{PE}$ & $S E$ & $\mathrm{PE}$ & $S E$ & \\
\hline & & & $0.28+$ & $(0.16)$ & $\begin{array}{l}\text { Students were more likely to select as a friend another student from the } \\
\text { same cohort (only marginal in model 2) }\end{array}$ \\
\hline Alter Cohort & $-0.41 * * *$ & $(0.12)$ & $-0.40 * *$ & $(0.13)$ & $\begin{array}{l}\text { Students from cohort A (compared to cohort B) were less likely to be } \\
\text { nominated as friends (less popular) over time }\end{array}$ \\
\hline Ego Cohort & -0.01 & $(0.12)$ & -0.03 & $(0.12)$ & $\begin{array}{l}\text { Students from cohort A and cohort B were equally likely to nominate } \\
\text { others as friends (activity). }\end{array}$ \\
\hline Homophily Gender & -0.03 & $(0.07)$ & -0.03 & $(0.08)$ & $\begin{array}{l}\text { Students were no more likely to befriend another student who was the } \\
\text { same gender as themselves }\end{array}$ \\
\hline Alter Gender & -0.06 & $(0.09)$ & -0.06 & $(0.09)$ & $\begin{array}{l}\text { Female students and male students were equally likely to be nominated } \\
\text { as friends }\end{array}$ \\
\hline Ego Gender & 0.06 & $(0.12)$ & 0.05 & $(0.11)$ & Males and females were equally likely to nominate others as friends \\
\hline \multicolumn{6}{|l|}{ Psychological Adjustment Influence } \\
\hline Rate Period 1 & 2.49 & $(0.88)$ & 2.39 & $(0.85)$ & $\begin{array}{l}\text { There were about } 2.5 \text { opportunities on average for students to increase } \\
\text { or decrease their level of psychological adjustment between T1 and T2 }\end{array}$ \\
\hline Rate Period 2 & 2.99 & $(1.16)$ & 3.06 & $(1.17)$ & $\begin{array}{l}\text { There were around } 3 \text { opportunities on average for students to increase or } \\
\text { decrease their level of psychological adjustment between T2 and T3 }\end{array}$ \\
\hline Linear Shape & 0.14 & $(0.17)$ & -0.00 & $(0.17)$ & Taken together the linear and quadratic shape reflects the unimodal \\
\hline Quadratic Shape & -0.01 & $(0.12)$ & -0.05 & $(0.12)$ & distribution of Psychological Adjustment over time \\
\hline Social Influence Contagion (H3) & -0.11 & $(0.62)$ & -0.12 & $(0.67)$ & $\begin{array}{l}\text { Students with a friendship tie with another student with a higher level of } \\
\text { psychological adjustment did not improve in their level of adjustment }\end{array}$ \\
\hline Effect from Local & -0.00 & $(0.29)$ & 0.30 & $(0.32)$ & $\begin{array}{l}\text { Local students and international students were comparable in their level } \\
\text { of psychological adjustment }\end{array}$ \\
\hline Effect from South Asia & 0.30 & $(0.42)$ & -0.01 & $(0.43)$ & $\begin{array}{l}\text { SA students and non-SA students were comparable in their level of } \\
\text { psychological adjustment }\end{array}$ \\
\hline $\begin{array}{l}\text { Effect from Sociocultural } \\
\text { Adjustment }\end{array}$ & $0.39 \dagger$ & $(0.21)$ & $0.39 \dagger$ & $(0.21)$ & $\begin{array}{l}\text { Students with a higher level of sociocultural adjustment tend to increase } \\
\text { their level of psychological adjustment (marginal in both Models) }\end{array}$ \\
\hline
\end{tabular}


Table 1 (continued)

\begin{tabular}{|c|c|c|c|c|c|}
\hline & \multicolumn{2}{|c|}{ Model 1} & \multicolumn{2}{|c|}{ Model 2} & \multirow{2}{*}{ Result Interpretation } \\
\hline & $\mathrm{PE}$ & $S E$ & PE & $S E$ & \\
\hline \multicolumn{6}{|l|}{ Sociocultural Adjustment Influence } \\
\hline Rate Period 1 & 2.49 & $(0.76)$ & 2.46 & $(0.86)$ & $\begin{array}{l}\text { There were around } 2 \text { opportunities on average for students to } \\
\text { increase/decrease their sociocultural adjustment level between } \mathrm{T} 1 \text { and } \\
\mathrm{T} 2\end{array}$ \\
\hline Rate Period 2 & 2.99 & $(1.12)$ & 3.00 & $(1.33)$ & $\begin{array}{l}\text { There were around } 3 \text { opportunities on average for students to } \\
\text { increase/decrease their sociocultural adjustment level between } \mathrm{T} 2 \text { and } \\
\mathrm{T} 3\end{array}$ \\
\hline Linear Shape & 0.14 & $(0.12)$ & 0.14 & $(0.12)$ & Taken together the linear and quadratic shape reflects the unimodal \\
\hline Quadratic Shape & -0.01 & $(0.11)$ & -0.00 & $(0.11)$ & distribution of Sociocultural Adjustment over time \\
\hline Social Influence Contagion (H4) & 0.36 & $(0.48)$ & 0.35 & $(0.50)$ & $\begin{array}{l}\text { Students with a friendship tie with another student with a higher level of } \\
\text { sociocultural adjustment did not improve in their level of adjustment }\end{array}$ \\
\hline Effect from Local & 0.22 & $(0.27)$ & 0.23 & $(0.29)$ & $\begin{array}{l}\text { Local students and international students were comparable in their level } \\
\text { of sociocultural adjustment }\end{array}$ \\
\hline Effect from South Asia & 0.25 & $(0.45)$ & 0.25 & $(0.46)$ & $\begin{array}{l}\text { SA students and non-SA students were comparable in their level of } \\
\text { sociocultural adjustment }\end{array}$ \\
\hline $\begin{array}{l}\text { Effect from Psychological } \\
\text { Adjustment }\end{array}$ & $0.34+$ & $(0.19)$ & $0.34 \dagger$ & $(0.19)$ & $\begin{array}{l}\text { Students with a higher level of psychological adjustment tend to } \\
\text { increase their level of sociocultural adjustment (marginal in both } \\
\text { Models) }\end{array}$ \\
\hline
\end{tabular}

Note. Values in parentheses are $S E . \dagger p<.10,{ }^{*} p<.05,{ }^{* *} p<.01,{ }^{* * *} p<.001$ (two-tailed test) 


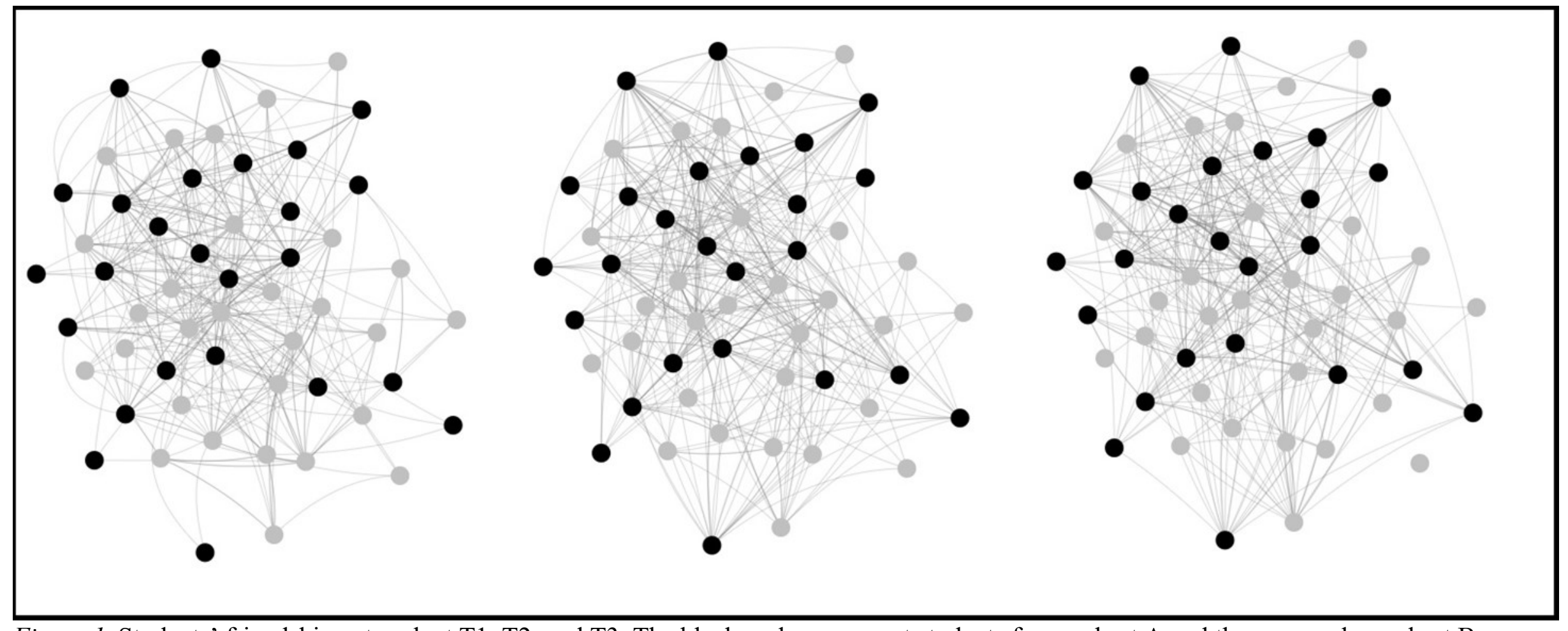

Figure 1. Students' friendship network at T1, T2, and T3. The black nodes represent students from cohort A and the grey nodes, cohort B. 


\section{University Library}

\section{- M M N E R VA A gateway to Melbourne's research publications}

Minerva Access is the Institutional Repository of The University of Melbourne

Author/s:

Sadewo, GRP;Kashima, ES;Gallagher, C;Kashima, Y;Koskinen, J

Title:

International Students' Cross-Cultural Adjustment: Social Selection or Social Influence?

Date:

2020-06-08

Citation:

Sadewo, G. R. P., Kashima, E. S., Gallagher, C., Kashima, Y. \& Koskinen, J. (2020).

International Students' Cross-Cultural Adjustment: Social Selection or Social Influence?. JOURNAL OF CROSS-CULTURAL PSYCHOLOGY, 51 (6), pp.490-510. https:// doi.org/10.1177/0022022120930092.

Persistent Link:

http://hdl.handle.net/11343/252747 